\title{
Ética como jogo de cena
}

\section{Ética como juego de escena}

https://doi.org/10.34112/2317-0972a2018v36n73p105-118

Pedro Felipe M. de Araújo ${ }^{1}$

Luis Antonio dos Santos Baptista ${ }^{2}$

Resumo: Tendo como foco o documentário Jogo de cena, de Eduardo Coutinho, o artigo objetiva propor questionamentos acerca das posturas dominantes de interpretação sobre o sujeito de uma história narrada. Deseja também apresentar outras possibilidades de sentido do que seja a alteridade no convívio com a diferença. O filme, ao situar a cena da fala como um jogo aberto, se desloca da busca de uma estável verdade sobre si que o outro revelaria. Esse deslocamento desprivatiza a esfera do íntimo, possibilitando a produção de uma obra aberta, que torna inoperante uma leitura única. Inspirado nas contribuições de Walter Benjamin, entre outros autores, pretende-se ressaltar a aposta de uma ética que promova percepções de mundo que não se esgotem na tentativa de classificar uma narrativa no âmbito identitário ou privatizante da subjetividade. A ética como jogo político onde histórias recusam a conclusividade do fim.

Palavras-chave: Cinema documentário; subjetividade; ética.

ABStRAct: Focusing on Eduardo Coutinho's documentary Jogo de Cena, this article proposes questioning dominant postures of interpretation of characters of a narrated story. It also presents other possible meanings to what otherness is when dealing with difference.

1. Universidade Federal Fluminense, Niterói, RJ, Brasil.

2. Universidade Federal Fluminense, Niterói, RJ, Brasil. 
The film, by situating the speech scene as an open game, shifts from the search for a stable truth that the other might reveal. This shift de-privatizes the intimate sphere, enabling the production of an open artwork, which renders a single reading inoperative. Inspired on contributions by Walter Benjamin, among other autors, we have emphasized the commitment of an ethics that promotes perceptions of the world that are not exhausted in the attempt of classifying a narrative in the identity or privatizing scope of the subjectivity. Ethics is understood as a political game where stories refuse the conclusiveness of an end.

KeYWoRds: Documentary; subjectivity; ethics.

Em 2006, foi realizado um convite público para mulheres quaisquer que tivessem histórias para contar. A posteriori, também foram convidadas algumas atrizes - conhecidas ou não - para (re) encenar os relatos previamente selecionados. Pelo filme, saberemos apenas da primeira parte desta metodologia. Aqui, o lócus da cena em que ocorrerão as conversas não será uma dada comunidade estabelecida de pessoas ou um território geográfico circunscrito, mas o palco de um teatro vazio. Como um ensaio fílmico, Jogo de cena compõe-se na "tensão entre construção e expressão" (XAVIER, 2013), utilizando-se da própria estrutura narrativa para evidenciar sua carga dramática. No ensaísmo há uma ênfase na forma, que é de onde surgem os procedimentos reflexivos da matéria fílmica. O pensamento do filme sobre si próprio compõe a imanência da montagem, uma espécie de "forma que pensa", como expressa Jean-Luc Godard sobre o filme-ensaio. Jogo de cena aprofunda o debate das relações documentais entre o efeito-câmera ${ }^{3}$ proveniente dos artifícios cinematográficos, junto a certa estética performativa $a^{4}$ na busca das personagens - tensionamento já trabalhado por Coutinho em seu “dispositivo" documentário, mas que neste filme ganha novas espessuras. Importante salientar que todo esse denso jogo reflexivo não se desvincula do plano afetivo que habita as imagens, pois o filme não acontece “sem a sedução emocional do espectador" (FELDMAN, 2010, p. 149). Porém, uma

3. Na sociedade do espetáculo, o efeito-câmera seria "aquela instância do olhar que estrutura um campo do visível e lhe confere uma dimensão de cena cujo desdobramento é se fazer imagem pública”. Não se furtando a este efeito de interferência sobre a performatividade daquele que fala para a câmera, certo documentário brasileiro contemporâneo tem buscado "novas alternativas para lidar com o efeito câmera e direcioná-lo para a construção de personagens sem os constrangimentos trazidos pelo protocolo do espetáculo e seu voyeurismo [...]” (XAVIER, 2013).

4. “[ ... tem como horizonte a apresentação de um sujeito como foco de um estilo [... ] recuperam na conversa um sentido de autoconstrução que tem sua dimensão estética” (FELDMAN, 2010, p. 156). 
sedução particular: na tela, histórias e autores previsíveis darão lugar à emoção do estranhamento da narrativa, em que a opacidade de quem a conta é afirmada.

Diante de toda sorte de programas televisivos que sustentam o espetáculo de "eus já acabados" - das saturadas formas de entrevista e reportagens de opinião às exposições da intimidade sob as variadas capturas subjetivas dos reality shows -, é sugerido que nos sintamos contemplados afetivamente pela "eloquência do confessional midiático" (BRUNO, 2014, p. 83). Por quais caminhos nos emocionamos? O filme, ao situar a cena da fala como um jogo aberto, se desloca da busca de uma estável "verdade sobre si" que o outro revelaria, escovando a contrapelo o real de uma história, ao privilegiar a "opacidade e a tensão entre as subjetividades e seus horizontes ficcionais" (FELDMAN, 2010, p. 161). Essa transgressão que desprivatiza a esfera do íntimo realça o momento do corpo que fala, que gesticula, que desconcerta e emociona. Jogo de cena é um "filme lacrimoso" (BRAGANÇA, 2007): dramas íntimos, perdas familiares, desilusões amorosas, causos engraçados, lutos superados, relações irresolutas, sonhos balsâmicos que fazem a vida seguir. $\mathrm{O}$ que moveu aquelas mulheres a se direcionarem para um teste de documentário, para contar uma história tão particular? Onde estão as atrizes para além da representação?

Em Jogo de cena, Coutinho, com ajuda da montadora Jordana Berg, apresenta seudocumentário composto por um coro dessas múltiplas vozes femininas. Montagem de imagens e palavras que se desvencilham da "dona" de cada história; ocupam o palco de um teatro vazio, intensificando "o drama microscópico" do rosto, esse momento de verdade que só acontece no cinema e é exclusivo dele (XAVIER, 2013, p. 613). O rosto onde se justapõem cidades, histórias incompletas, outros corpos, embates de sentidos díspares, compondo um coletivo invisível projetado na sala escura.

O "filme lacrimoso" no cenário do teatro inabitado diferencia-se de outras obras cinematográficas em que a lágrima seria fruto de uma catarse, da emoção desencadeada pela imagem impregnada, como em um espaço doméstico, de significados, de rastros de um mundo familiar; catarse propiciada pelo reconhecimento e pela identificação. Das histórias sem dono, sem autor específico, sem o suporte do eu, um convite é feito para estranhá-las e continuarmos a contá-las. São emoções de um cotidiano paradoxalmente familiar e estranho apresentado por contadoras de histórias que recusam indicar - através dos seus rostos, identidades, vestígios culturais - a conclusão do que é narrado. Indefinição dos espaços vazios, onde a trama de uma história por vir poderá ser ensaiada. Convite arriscado, proposto por uma 
aposta ética em que a catarse não teria lugar. $\mathrm{O}$ que nos faz crer, ou duvidar, ou nos engajar naquilo que vemos e ouvimos? Como a cena nos convoca ao jogo:

"CONVITE - Se você é mulher com mais de 18 anos, moradora do Rio de Janeiro, tem histórias pra contar e quer participar de um teste para um filme documentário, procure-nos". Assim estava nos classificados de um jornal carioca em 2006, e assim nos aparece na imagem, que serve como plano inicial do filme Jogo de cena. Será a única referência que teremos antes de encontrar essas mulheres. $\mathrm{O}$ "procure-nos", ao fim do convite, é revelador, por banal que pareça. Coutinho sempre foi ao encontro dos seus personagens, partindo de certo rigor metodológico que relacionava deslocamento territorial e curiosidade pelos "narradores de si mesmos". Aqui, parte-se de uma premissa de que essas mulheres sentir-se-iam dispostas a ir ao encontro de alguém; ir contar suas histórias. O que as move para este encontro?

Sons de passos no escuro da tela, um corpo de uma mulher surgindo numa escada em espiral começa a iluminar-se, ao brotar do fundo do teatro. No palco, uma equipe de cinema está montada para filmar aquele encontro, presenciar aquela história. A câmera aponta para o sentido da plateia. Ainda no palco, entre a câmera e a plateia, uma cadeira a ser preenchida. Atrás dela, vemos todas as cadeiras restantes do teatro que permanecerão vazias. Este é o cenário do jogo. $\mathrm{O}$ vazio do espaço afirma que algo irá acontecer.

A primeira personagem chega ao palco, senta na cadeira e inicia sua história. Fala do sonho que a acompanhou de ser atriz, e de como teve que ralar e esperar para realizá-lo. Hoje é atriz e atua no grupo Nós do Morro. A personagem que está encenando no momento, em montagem do grupo, é a Joana ("Medeia"), da peça A Gota D'água ${ }^{6}$. A Medeia, na mitologia grega e na peça, assassina os próprios filhos envenenados, para que eles não venham a morrer de sofrimento pelo mundo. A pedido de Coutinho, ela "encena" sua última fala da peça, seu discurso sobre a morte de seus filhos. Fala todo o texto e, antes de desaparecer do filme, conclui sua

5. "O toque de Coutinho é buscar o que os personagens evidenciam de singular, e não pelo que representam ou ilustram na escala social. Resulta um movimento afirmativo na voz e performance de 'narradores de si mesmos' empenhados em sua autoconstrução como personagens que moldam um estilo” (XAVIER, 2013, p. 608).

6. Peça de autoria de Chico Buarque e Paulo Pontes, escrita em 1975, baseada numa adaptação de Vianinha da encenação grega de Eurípedes sobre o mito da Medeia. 
cena: "daí eu saio e volto morta". Diante da já sabida importância dada por Coutinho para os primeiros minutos de seus filmes - seja pelas descrições do método ou pelo impacto difuso de uma cena -, o que haveria desta Medeia, da Joana, nas mulheres do filme?

A próxima personagem conta que é espírita, e que foi a partir de um sonho que ela recebeu o sinal de que teria que assumir uma responsabilidade; no outro dia acordou com uma sensação ruim. Ela então se vê grávida de seu segundo filho, mas planeja e deseja sua vinda. Diz que no dia do nascimento, no momento do parto, seu "bebê" sofre complicações severas e naquele dia mesmo "desencarna". Durante a noite ela tem um sonho e uma visão, de que estava num hospital junto com uma criança de 11 anos, muito debilitada. Remete este episódio ao fato de que, se seu "bebê" continuasse vivo, seria um sofrimento, tanto para ela quanto para ele. Durante seu relato há uma frase que passaria despercebida, mas que se tornou emblemática em relação ao jogo que o filme nos propõe: "Eu saí um pouco do foco do casamento". Sucede um corte na montagem da cena, ocorrendo a transição entre o corpo de uma mulher que foi contar sua história para um teste de um filme documentário e o de uma atriz consagrada, que continua a contar a história. Vemos agora em cena Andréa Beltrão, que repete a frase dita e faz seguir o relato. Ficamos nós, espectadores, também, levemente desfocados. Há uma diferença de tom na encenação da atriz - pequenas pausas na fala que não vimos na outra contadora -, como se uma outra arquitetura de voz fosse emergindo sob o manto da mesma história. O ritmo da narrativa faz a costura e nos mantém acesos, nas passagens pelos diferentes corpos que são, ao mesmo tempo, registro e representação. Em um dos momentos em que a atriz encena o relato que the foi endereçado, ainda ao falar sobre a morte prematura de seu segundo bebê, ela se emociona e chora. Interessante perceber que a própria "dona da história", quando a relata para Coutinho, não chega a verter lágrimas. Quando Coutinho e Andréa estão conversando sobre a atuação, ela fala de sua relação com a narrativa da mulher, diz que não conseguia "passar o texto" sem se emocionar. Para fazer o filme, ela fala que até tentou segurar, mas que não suporta contar aquilo e não chorar. Tenta se explicar, diz que talvez seja porque não acredita em nada, que para ela é "morreu, morreu", e para alguém que possua alguma crença possa se tornar mais fácil este momento. Admite ainda que teria que ensaiar muito para poder alcançar a "serenidade" da fala da mulher. A história encenada parece incidir diretamente sobre a representação da atriz e mexer com 
sua percepção de mundo. Os relatos, as cenas dessas duas mulheres também nos tocam e movem nossa atenção, suas distâncias nos aproximam.

$\mathrm{O}$ jogo das encenações segue desfolhando suas camadas. A fala da atriz de Medeia retorna sutilmente entre os cortes, "daí eu saio e volto morta". A nitidez de um rosto familiar, o gesto reconhecível ou qualquer pronome pessoal fenecem através do jogo de cenas. Morte do autor da história, morte e vida, ofertadas pelo cinema, que enfrentam sufocantes limites do real ou de um corpo.

Logo após Andréa Beltrão, um rosto não conhecido ocupa a cadeira. E nos conta um flerte amoroso que viveu, de como gerou sua gravidez e que tem batalhado muito para cuidar sozinha da filha. Sua performance é descontraída, expõe um mundo rico em detalhes e assertivas cotidianas. Ao final de seu relato, mirando no que acreditamos ser os olhos de Coutinho, ela, com seu reluzente batom vermelho em close-up, fala:"é porque tem gente que passa o dia inteiro na rua e não olha pro céu, entendeu?"; e então vira seu rosto para a câmera, como se agora fitasse nosso olhar espectador e sentencia: "E foi isso que ela disse". Como assim, "foi isso que ela disse"? Quem é "ela", senão esta que agora nos conta sua história? O filme provoca uma espécie de curto-circuito: numa ruptura perceptiva através da imagem, somos lançados de maneira atroz para um local de suspeita, para a fragilidade de nossas certezas. Curiosamente, no link para assistir ao filme no Youtube , o comentário com mais votos é um relacionado exatamente a esta cena, que a comenta "Foi isso que ela disse' [espaçamento] 'Fui jogado pro precipício'”.

O filme segue se enredando por estas cenas que interrompem a continuidade dos sentidos, que põem o ser de cada história em questão, ao desvincular os relatos dos corpos que falam, jogando com as nuances de suas presenças. As narrativas passam a existir por si sós, ganham outros relevos que margeiam as fronteiras do real e do ficcional. As personagens tornam-se apenas as hospedeiras da fala, afrouxando-se o controle sobre o efeito de veracidade que elas provocam. A própria noção de sujeito é questionada "enquanto ser que expressaria sua subjetividade com palavras e lágrimas" (BERNARDET, 2013, p. 626). O abismo sugerido pelo comentarista anônimo do Youtube nos evidencia que é a força de "autenticidade produzida na encenação" (XAVIER, 2013, p. 611), do relato misturado à performance da personagem, que indicia nossa confusão sobre a importância do factual naquilo que vemos e ouvimos. Tal como centelhas que saltam

7. Ver o link: <https://www.youtube.com/watch?v=DziVbTRGEgw > (O link anterior, que continha o filme completo e o comentário citado, foi retirado do ar devido a direitos autorais sobre a obra. De qualquer maneira, neste novo link, o filme pode ser assistido na íntegra). 
de um centro a outro, as histórias circulam por entre esses corpos falantes em cena. É a própria ilusão de subjetividade $e^{8}$ que nos mobiliza no farejar de uma existência que ali se põe em jogo. Ilusão potente que põe à prova naturalizações de modos de existir, do tempo, do real. A ilusão do truque da arte, do jogo de cenas, que remete a subjetividade à criação processada por infindáveis ensaios. A ilusão que não se opõe ao real, mas o viola.

A forma do ensaio, como tessitura narrativa que decompõe a si mesma em ato, pode se aplicar ao filme na maneira como este opera os trajetos singulares das personagens, junto às aberturas afetivas de suas performances. Como modalidade de pensamento, o ensaísmo parte da admissão de que o sujeito moderno já é "atravessado, trabalhado e fracionado pela ficção" e que, no caso do cinema documentário, em filmes onde o falar sobre si é uma de suas forças, poderíamos dizer que qualquer "auto-elaboração é uma autoficção" (FELDMAN, 2010, p. 150) a ser mediada pela presença da câmera. Para o cineasta Jean Rouch - que dissera ser a ficção o único caminho para se penetrar a realidade -, a câmera não seria, no cinema documentário, um obstáculo que atrapalharia a expressão dos personagens, "mas uma testemunha indispensável que motivará sua expressão" (XAVIER, 2013, p. 152).O problema do verdadeiro e do autêntico no campo do documentário não se esquiva aos efeitos e às construções ficcionais provocados no real, pois são construídos nos embates da câmera com o mundo. A câmera não seria apenas registro do que já estaria enquanto verdade no real, mas antes de tudo o forja, produz um recorte do real junto aos personagens em cena. Assim, tal como a máscara da tragédia grega, "que oculta ao mesmo tempo que revela, ou revela justamente porque oculta”, as práticas ensaísticas contemporâneas investem na opacidade de seus meios, no intuito de problematizar os enunciados do pensamento ocidental, originários de nossa tradição socrático-platônica, que se ancora nos binarismos "essência-aparência, profundidade-superfície, autenticidade-encenação e realidade-ficção" (XAVIER, 2013, p. 152). Tudo que há no âmbito do ensaio documental é a verdade do cinema', e Jogo de cena nos mostra como esta é indecidível.

8. “[...] o filme é uma poderosa reflexão sobre a construção da subjetividade, a subjetividade não como essência mas como produção, a transformação de episódios vividos em narrativas, autonomização das narrativas que, a partir desse momento, só expressam uma ilusão de subjetividade.” (BERNADET, J., 2013, p. 635).

9. Aqui lembramos do conceito de "verdade da filmagem", cunhado por Coutinho, que se aproxima deste tipo de crença frente ao poder provisório da imagem em produzir suas próprias verdades. (COUTINHO, 1997). 
Importante salientar que essa aproximação teórica ao método do ensaio, por mais ampla que possa se apresentar como forma fílmica, não é desligada de um certo rigor composicional que dialoga com o substrato do que é entoado pelas mulheres em cena. "A teoria vem durante os fatos", como sinaliza o próprio Coutinho em uma entrevista dada após a feitura deste filme ${ }^{10}$. Quando vemos a atriz Fernanda Torres entrar em cena, ainda no primeiro terço da projeção, logo a reconhecemos. Só que ela parece estar contando uma "história sua", pois menciona uma tia que é mãe de santo e até um apelido ("Nanda") durante o relato. Aqui seria ela a atriz convidada ou a personagem que deseja contar sua história? Fala de um acontecimento que vivenciou junto com sua tia, num terreiro de Candomblé. Atravessou uma noite dentro de um espaço onde ocorreu um ritual, uma espécie de cura para ela. Essa dimensão etérea que se ambienta no filme, entre experiências religiosas e relatos oníricos, retorna em diversos momentos, o que parece colocar um "tempero do incerto" a mais na discussão aberta pelo próprio modus operandi da forma no ensaio.

Seguindo o ritual do início do filme, vemos uma jovem subir as escadas do teatro. Fica espantada com a quantidade de pessoas que encontra em cima do palco, enquanto vai se acomodando na cadeira reservada: "quanta gente!", diz ela. Coutinho chama atenção para o fato de que ninguém tinha dito isso até então. Há um corte, e vemos o mesmo plano dessa cadeira vazia com a chegada de Fernanda Torres, apresentando um similar espanto, ao repetir "quanta gente!". Coutinho pontua que achou curioso que Fernanda tenha, desde já, começado a encenar o texto. Fernanda diz que acha interessante evidenciar a surpresa da jovem naquele momento, iniciar já dali, e em seguida Coutinho pontua: "fica parecendo que a gente não se viu". Conversando com Coutinho, nesses primeiros momentos de sua chegada, ela tenta se explicar, achando que não conseguiu contar no teste nada que tenha tido algum sentido:"No final eu não contei nada, eu fracionei um monte de história, mas... você achou que teve continuidade?". A escolha das imagens para o filme - por exemplo, até que ponto uma fala se estenderá no plano ou quando acontece um corte abrupto na cena - parece evidenciar a estrutura da montagem cinematográfica e a forma como Coutinho se apropria e reposiciona as falas no filme para tecer sua própria narrativa. O que seria a atividade, ou a dúvida-chave lançada para Coutinho pelo próprio filme, se não esta indagação da jovem, sobre fracionar e continuar histórias? É como se Coutinho estivesse também conversando conosco, espectadores: o

10. Entrevista concedida a Felipe Bragança, intitulada Palavra e superfície (BRAGANÇA, 2008). 
documentário torna-se uma forma para anunciar os dilemas vividos por aquele que tenta organizar este mosaico de relatos. Voltamos com Fernanda Torres, que volta a encenar o relato da jovem. Logo nos primeiros momentos ela dá uma pausa e silencia, parece titubear, não sabemos se aquelas expressões de silêncio ou de olhar no horizonte são representações da Aletta ou suas próprias. Sim, descobrimos em meio à conversa que a jovem espantada se chama Aletta, cujo nome remete à aletheia ${ }^{11}$ grega, "a verdade no sentido da revelação", como explica Fernanda, ao representá-la.

$\mathrm{O}$ jogo entre as encenações se complexifica, o filme segue alternando a presença das duas, nem sempre continuando pelos mesmos pontos do relato. Fernanda, em certo momento, fica visivelmente perplexa. Tenta se concentrar, mas está tendo dificuldades em contar aquela história para Coutinho, diz que parece estar mentindo, tão embaralhada como nós. Fala que não sabe muito bem por que está mentindo, é como se não conseguisse "separar ela do que ela diz". Sob tímidos risos, Fernanda aprofunda seu próprio dilema na posição de atriz diante de Coutinho, diz que representar "dá vergonha", e que aquela gravação "tem ar de teste". Após essa primeira pausa, ela volta ao relato, mas depois de algumas palavras ela retorna para um estado silencioso. Seu rosto se mostra como um deslizar de dúvidas, ao fitar o horizonte incerto por trás da câmera, e quase como num estado de letargia ela murmura "que loucura, Coutinho, que loucura...". Nessa abertura de fronteiras entre o real e o campo ficcional que o filme se permite, Coutinho e Fernanda conversam mais um pouco sobre as questões da encenação. Ela diz que, quando teve acesso ao material filmado do relato da Aletta, preferiu não ver o recorte já editado por Coutinho, mas escolheu estudar sua fala a partir do "material bruto" da filmagem, pois este seria para ela "a memória" que teria da personagem. Podemos fazer aqui uma alusão ao ofício da montagem cinematográfica, pois Coutinho também se vale de todo o material bruto de conversas filmadas como seu parâmetro de edição, sua "parcela de memória" para dar conta do relato do outro e do que viveu, enquanto documentarista no encontro.

Há nesta mesma conversa uma bonita fala em que Fernanda Torres pondera sobre os limites da representação, dizendo que "o personagem real esfrega na sua cara onde poderia estar e não chegou". Ela diz que pela ficção você pode chegar a um nível de atuação e incorporação do personagem, que o "faz parecer real". O gesto ensaístico em

11. Para os gregos antigos, Alétheia designava verdade e realidade, simultaneamente. "Etimologicamente, a aletheia grega é formada por a+lethé, isto é, a negação (o prefixo "a”) daquilo que estaria oculto, obscurecido ou esquecido ("lethé”). A verdade, portanto, em grego, está etimologicamente relacionada à memória." (FELDMAN, 2010, p. 156). 
Jogo de cenaparece agir como uma problematização da própria aposta documentária de Coutinho, ao interrogar e desfiar o ato narrativo/performativo em sua eficácia dramática. Ao borrar os efeitos de verdade que circulam entre as histórias (re)vividas ao serem contadas - como de suas encenações para a câmera -, é a variação performática das personagens que explicita a centralidade dessas ambivalências, "que tornam inócuas as tentativas de separar, de um lado, a esfera do sujeito e seu 'núcleo interior' e, de outro, o campo intersubjetivo da cena" (XAVIER, 2013, p. 626).

Há no filme este aspecto de "obra aberta" que $\mathrm{o}$ ato fílmico e o pensar sobre si próprio se justapõem, que torna inoperantes as ferramentas críticas que busquem encontrar uma leitura única. $O$ desenrolar da obra nos convoca a estar lado a lado com ela, atentos a cada cena, imersos em cada rosto. Certo "distanciamento crítico", que almeja se erigir por um caminho de desvelamento das aparências, perderá o jogo frente às ambiguidades sustentadas pelas imagens desses encontros. A pesquisadora Ilana Feldman (2010, p.159) afirma que uma relação possível com o filme passaria pelo engajamento crítico que o filme propõe, em que "a dimensão afetiva da reflexão sobre o método soma-se à sedução emocional do espectador", o qual seria convocado a se engajar na situação implicada "tanto pelo efeito-câmera quanto pelas performances - da retórica, dos gestos e da memória - diante da câmera”. Assim, a interpretação ou a avaliação sobre o filme não caberia a julgamentos e análises de instâncias superiores, por onde correria a verdade; estaria mais em jogo aqui a produção de afetos de verdade, em que as personagens e suas encenações seriam avaliadas "em relação à vida e à intensidade que suas presenças e suas performances implicam", posicionando a relação afetiva "como avaliação imanente, em vez do julgamento como valor transcendente" (FELDMAN, 2010, p. 159).

A montagem do filme atualiza essas memórias singulares que ali são (re)vividas, são catalisadas por Coutinho dentro deste "pacto autobiográfico" ${ }^{13}$; da performance afetiva que acontece na tela e nos mostra as profundidades de sua superfície que

12. Lembremos aqui do livro Obra aberta, escrito por Umberto Eco e publicado em 1962, onde cunhou oconceito de "obra aberta" para apreender criticamente a arte do século XX. "Tal conceito define a obra de arte como algo inacabado que exigiria do receptor, no ato da fruição, uma participação bastante ativa a fim de perceber a obra como um objeto aberto a várias possibilidades interpretativas.” (MENDONCA; OLIVEIRA, 2010).

13. "E cabe ao entrevistador, com sua performance, catalisá-la. Assim faz Coutinho, mestre na procura de narradores e na interação, em cena, com essas figuras que, dentro do 'pacto autobiográfico', trabalham a sua imaginação para se identificar, num certo estilo, com a construção aqui e agora de um percurso a que dão vida de modo convincente". (XAVIER, 2013, p. 622). 
fogem dos invólucros identitários. O filme presentifica a emoção do lembrar, sem fornecer cordas que as prendam; dá tempo para que as personagens se transformem em cena, nos contradigam e nos confundam, pois também nos modulamos quando as testemunhamos. Convoca-nos a oferecer espaço para perder o controle e deparar com a ênfase da encenação, observar a automise-en-scène ${ }^{14}$ de cada uma como "expressão de uma experiência e uma imaginação" (XAVIER, 2013, p. 617). Como não se surpreender quando a personagem da Jackie Brown, no meio do filme, canta num rap de sua autoria toda a história que pensávamos ser da primeira pessoa em cena, a menina que virou atriz de uma tragédia grega? Como definir as ambiguidades que surgem na imanência dos relatos, quando, em meio a um duro processo de luto pela perda do filho, a mãe chega em casa, depois de meses internada sob o impacto dessa morte, e percebe que raízes de leguminosas floresceram dentro da geladeira, evocando a bela imagem de "um jardim de comida brotada"?

O filme-ensaio ativa nossa experiência sensível, nos transforma em pontos por onde o jogo da cena continua a irradiar suas intensidades de conexão para o além-filme. A ficção documentária perturba e assalta os grilhões de nossa vigília, implodiria o "universo carcerário"nesta bela expressão sugerida por Benjamin (1996, p. 189) sobre o potencial onírico aberto pelo nascimento do cinema. Para o filósofo berlinense, "O cinema faz-nos vislumbrar, por um lado, os mil condicionamentos que determinam nossa existência, e por outro assegura-nos um grande e insuspeitado espaço de liberdade" (BENJAMIN, 1996, p. 189). Como diria Comolli, "a posição de controle é insustentável, tanto no cinema quanto na vida" (FELDMAN, 2010, p. 153).

Ao fim do filme, vemos a única das mulheres que pediu para voltar à cena, pois tinha achado sua participação "meio barra pesada", tinha "ficado triste", e ela não queria ficar triste. Diz que gostaria de cantar uma música, porque "música sempre quebra um pouco, né?". Coutinho pergunta se ela quer cantar uma música que teria "algum significado para ela, ou sei lá.", o que ela completa: "Ah, aí tem o mundo, né?", mas Coutinho fala que o "mundo não dá", e indaga se teria "alguma que marcou, assim, que justifique que você cante ela". Responde a mulher: "ficar presa no passado, acho estranho isso", ao que Coutinho retruca: "tudo bem que seja no passado, mas o

14. "[... ] a auto-mise-en-scène seria a combinação de dois movimentos. Um vem do habitus e passa pelo corpo (o inconsciente) do agente como representante de um ou de vários campos sociais, o outro tem a ver com o fato de que o sujeito filmado, [...] se ajusta à operação de cinematografia, nela coloca em jogo sua própria mise-en-scène, no sentido da colocação do corpo sob o olhar, do jogo do corpo no espaço e no tempo definidos pelo olhar do outro (a cena)". (COMOLLI, 2008, p. 85). 
passado e o presente é a mesma coisa, né?", e ela completa: "mais ou menos porque as pessoas não conhecem". Ela se emociona, ao lembrar-se do pai, das músicas que ele cantava para ninar seu sono, e que ela cantava para ninar sua filha. Coutinho pede então que cante uma dessas, e antes de começar, ela, ainda emocionada, lança sua última pergunta: "como é que eu vou cantar chorando?". E então entoa a cantiga popular Se essa rua fosse minha, com rosto e voz visivelmente lacrimosos.

Em meio a sua performance, ouvimos a voz da atriz Marília Pêra murmurar, fora de cena, os versos da música logo na sequência do canto da personagem, como se fosse o sussurro de um fantasma, da atriz que busca os rastros da voz e do rosto de sua personagem, quase como o desejo sem feição do cinema que imita a vida $a^{15}$, perscruta (re)vivê-la.

Re-viver a vida, esse sonho de fantasmas que somos, reviver a vida é o que o teatro procura, é o que as mulheres-atrizes procuram em seus sonhos de redenção, é o que o drama procura em sua religação com o gesto sem tempo. Não a água que sai do olho do cristal japonês que Marília nos mostra, mas o choro como o composto todo do corpo que se esconde, que se disfarça [...] (BRAGANÇA, 2007).

"Se eu roubei, se eu roubei teu coração, é porque tu roubaste o meu também" é o último verso da música. Ouvimos estas palavras entrelaçadas nas vozes de ambas. No silêncio que segue após o canto, vê-se um plano do mesmo palco de teatro, agora como se fosse um olhar distante advindo da plateia. Sem nenhum dos equipamentos anteriores, vemos apenas duas cadeiras vazias, assim como todas as poltronas presentes - quase sugerindo que tudo aquilo que aconteceu também tenha sido apenas um sonho ou só encenação, ou só ali no filme, ou não mais. A precariedade da nudez do cenário colide com as memórias com que acabamos de nos deparar em filme. O precário presente em uma aposta ética particular: a potência política do inacabamento de uma história e da renúncia à autoridade do autor. Sobre essa renúncia, Jean Marie Gagnebin (1994, p. 94), inspirada em Walter Benjamin, argumenta: "Paradoxalmente, a renúncia à autoridade do autor permite a eclosão de um texto luminoso no qual ele reaparece como uma voz narrativa única, surgindo do entrelaçamento da sua história com a história dos outros”. Luminosidade a incidir sobre as cadeiras vazias, a de Coutinho e de suas personagens,

15. 'A fantasmagoria daqueles rostos é a alma que as atrizes tentam sugar das mulheres 'reais', esses fantasmas imensos que são os rostos na tela grande e imensa desse cinema que imita a vida, que imita não por substituição, mas por desejo, por reverência”. (BRAGANÇA, 2007). 
que foram ocupadas para viver esse jogo - onde não cabe o mundo -, para poder montarmos outro, nos co-movendo com as histórias de outrem.

\section{REFERENCIAS}

BENJAMIN, W. Obras escolhidas. Magia e técnica, arte e política. Trad. Sérgio Paulo Rouanet. São Paulo: Brasiliense, 1996.

BERNADET, J. Jogo de cena. In: OHATA, Milton (Org.) Eduardo Coutinho. São Paulo: Cosac Naify, 2013. p. 627-636.

BRAGANÇA, F. (Org.). Eduardo Coutinho - Encontros. Rio de Janeiro: Beco do Azougue, 2008. . (Re)Viver a Vida, Revista Cinética, 2007. Disponível em: <ww.revistacinetica.com.br/ jogodecenafelipe.htm>. Acesso em: 25 jun. 2015.

BRUNO. F. Jogo de Cena. In: Máquinas de ver, Modos de ser - Vigilância, tecnologia e subjetividade. Porto Alegre, Editora Sulina, 2014. Disponível em: <http://www.editorasulina.com.br/detalhes. php?id=625> . Acesso em: 29 de Jun. de 2015.

COMOLLI, J. Sob o risco do real. In: .Ver e poder: A inocência perdida - cinema, televisão, ficção e documentário. Belo Horizonte: UFMG, 2008. p. 169-178.

COUTINHO, E. O cinema documentário e a escuta sensível da alteridade. In: Projeto História.

Revista do Programa de Estudos Pós-graduados em História e do Departamento de História da PUCSP, n. 15 (Dossiê Ética e História Oral), p. 165-170, 1997.

FELDMAN, I. Na contramão do confessional: O ensaísmo em Santiago, Jogo de Cena e Pan-Cinema Permanente. In: MIGLIORIN, C. (Org.) Ensaios no real - O documentário brasileiro hoje. Rio de Janeiro: Beco do Azougue, 2010.

GAGNEBIN, J.M. História e Narração em W. Benjamin. São Paulo: Perspectiva, 1994.

MENDONÇA, A. C. M. ; OLIVEIRA, A. P. Umberto Eco e o conceito de "Obra aberta". In: 62a Reunião Anual da SBPC, 2010, Natal. Anais/Resumos da 62 ${ }^{a}$ Reunião Anual da SBPC, 2010.

XAVIER, I. Jogo de cena e as outras cenas. In: OHATA, Milton (Org.) Eduardo Coutinho. São Paulo: Cosac Naify, 2013. p. 604-626.

\section{Filmografia}

COUTINHO, E. (Diretor). Jogo de cena. Rio de Janeiro: Video Filmes/Matizar, 2007. 105 min., som, cor. Disponível em: <https://youtu.be/DziVbTRGEgw>. Acesso em: 25 nov. 2012.

\section{SOBRe OS AUTORES}

Pedro Felipe Moura de Araújo é graduado em Psicologia (Universidade Federal da Paraíba), tem Mestrado em Estudos da Subjetividade (Universidade Federal 
Fluminense) e atualmente é Doutorando nessa mesma Universidade. Pesquisa e tem interesse nos seguintes temas: estudos contemporâneos da subjetividade; teoria e crítica da imagem; questões éticas e processos estéticos em humanidades. E-mail: peehfe@gmail.com.

Luis Antonio dos Santos Baptista possui mestrado em Psicologia - Psicologia Clínica (Pontifícia Universidade Católica do Rio de Janeiro), doutorado em Psicologia (Universidade de São Paulo) e pós-doutorado na Faculdade de Sociologia (Universidade de Roma, Itália). É professor titular do Instituto de Psicologia e do Programa de Pós-graduação em Psicologia da Universidade Federal Fluminense. Pesquisador do CNPQ, tem, como temas de interesse de pesquisa: experiência urbana e subjetividade e as problematizações da literatura e do cinema às produções políticas da diferença.

E-mail: baptista509@gmail.com.

Recebido em 27 de janeiro de 2018 e aprovado em 22 de março de 2018. 